\title{
DESLOCANDO SOBRE O ARCO-ÍRIS COM TONALIDADES CINZA E PRETO: ASSEXUALIDADES EM TRÂNSITO
}

\author{
MOVING ON THE RAINBOW WITHBLACK AND GAY SHADES: ASEXUALITIES IN TRANSIT
}

\section{RESUMO}

Este texto trata dos processos de subjetivação presentes na emergência da assexualidade visando observar algumas singularidades e particularidades no contexto contemporâneo. Realizamos um estudo da história da assexualidade a partir de um olhar foucaultiano e de um olhar rizomático efetuando, assim, uma interlocução entre as ideias de Michel Foucault,Gilles Deleuze e Felix Guattari. Nessa direção abordamos a assexualidade como possiblidade de orientação sexual, entendida como um não desejo sexual. Efetuamos ainda um processo de despatologização da assexualidade, como possibilidade efetiva.Como processo metodológico, utilizamos duas etapas: a netnografia e entrevistas semiestruturadas com indivíduos que se identificam como assexuais, posteriormente foi realizada a análise dessas falas e histórias, coadunando com o processo de autoidentificação. Concluímos que é necessário dar visibilidade à assexualidade, sustentando as relações de força presentes nesse tipo de orientação sexual.

Palavras-chave: Assexualidade. Genealogia. Netnografia. Gênero. Sexualidade.

\section{ABSTRACT}

This paper inquiry about the processes of subjectivity and the emergence of asexuality in order to observe some peculiarities and particularities in the contemporary context.We conducted a study of the history of asexuality from the perspective of Michel Foucault and a rhizomatic perspective making a dialogue between the ideas of Michel Foucault, Gilles Deleuze and Felix Guattari. We have described asexuality as a possibility of sexual orientation, perceived as a non-sexual desire and as a political act. We have gone through the depathologization process of asexuality as an effective possibility. We use a two-step procedure as a methodological process: netnography and semi-structured interviews conducted with individuals, who identify themselves as asexual, going through the analysis of these speeches and stories and associating it with the process of self-identification. We conclude that it is necessary to give visibility to asexuality sustaining the balance of power present in this sexual orientation.

Keywords: Asexuality. Genealogy. Netnography. Gender. Sexuality.

Luigi Silvino D'Andrea

Pontifícia Universidade Católica de Minas Gerais (PUC/MG). E-mail: luigiandrea74@gmail.com Roberta Carvalho Romagnoli

Pontifícia Universidade Católica de Minas Gerais (PUC/MG). E-mail: robertaromaı@gmail.com.br 


\section{Pelos caminhos da assexualidade}

Nesse artigo analisamos os processos de subjetivação de pessoas que se identificam como assexuais e suas reverberações em duas comunidades virtuais brasileiras que tratam da assexualidadeque, por sua vez, estão localizadas virtualmente na rede social Facebook e no site da AVEN (The Asexual Visibility E Education Network). A AVEN é a principal entidade que congrega assexuais e possui um site que conecta boa parte da comunidade assexual, apesar de existirem outros sites e blogs em várias línguas que seguem mesmo modelo ideológico (Brigeiro, 2013). A comunidade assexual atribui a ela a criação do termo "assexualidade" e sua importância se traduz na organização da maioria dos eventos online e offline ligados ao tema (Hinderliter, 2009a). Essas ações são realizadas pela AVEN ou por assexuais que se organizam em comunidades virtuais em redes sociais. Alguns eventos são feitos para aumentar a visibilidade dos assexuais, tais como a participação em Paradas de Orgulho LGBT e reportagens em sites e jornais, por exemplo (Mascarenhas, 2015), bem como na própria página da AVEN. Outros movimentos que podem ser mencionados nessa direção são os encontros aces, que têm sido realizados por assexuais que têm como objetivo conhecer seus pares. No Brasil, tais encontros são realizados regionalmente a partir das demandas dos próprios assexuais.

Segundo a AVEN (c2001-2012, tradução nossa), assexual é “[...] a pessoa que não experimenta atração sexual". ${ }^{1}$ Entretanto, Brigeiro (2013) considera que essa frase é simplista e imprecisa. Há outros teóricos que divergem da definição da AVEN. Carrigan (2013) realizou uma pesquisa utilizando triangulação de dados em que perguntava sobre o autoentendimento da assexualidade, recebendo respostas profusas e variadas sobre as orientações românticas dos sujeitos. O que se depreende daí é que a definição de que o assexual não experimenta atração sexual não apreende a variedade das experiências vividas pelos sujeitos que se identificam com essa classificação.

Um fator importante ao se delinear uma pesquisa sobre a assexualidade é a distinção entre orientação sexual e orientação romântica. Diamond (2008: 12) define a orientação sexual como sendo um "[...] padrão de desejo sexual consistente e estável por indivíduos do mesmo sexo, do outro sexo ou por qualquer dos sexos". Contudo, podemos questionar se o desejo sexual é realmente algo estável, além do fato de ele estar apartado de uma esfera ético-política.

Sobre a orientação romântica, Oliveira (2015) cita Esther D. Rothblum \& Kathleen A. Brehony (1993), autoras do livro Boston Marriages: romantic but asexual relationships among lesbians, publicado em 1993, no qual as autoras relatam a experiência de vários casais lésbicos que viviam uma relação estável sem a presença do ato sexual. Elas relatam que essa escolha pode se dar por incontáveis motivos comprovando que uma união afetiva não precisa estar efetivamente colada à sexualidade. Vale ressaltar que no estudo mencionado as autoras não rotulam

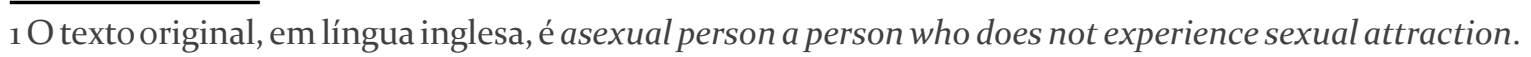


tais casais como assexuais e nem afirmam que todas as parcerias afetivas de cunho romântico sejam compostas por indivíduos assexuais.

Bogaert (2006), Diamond (2003; 2008) e Hinderliter (2009b) afirmam que há pluralidades de orientações e que há pessoas que se localizam na chamada gray area, isto é, com variabilidade no desejo sexual. Importante sublinhar, portanto, que existem variações de desejo sexual e de ligação romântica entre os que se identificam como assexuais e que, de fato, essa orientação sexual aflora cada vez mais no tecido social. No que se refere à assexualidade, Brigeiro (2013) pontua que esta não é uma escolha, mas uma condição. Descreve que a assunção de tal identidade depende de uma avaliação subjetiva. Esse autor extrai do site da AVEN uma definição geral:

A definição de assexualidade é 'alguém que não experimenta atração sexual'. No entanto, só você pode decidir que rótulo melhor lhe convém. A leitura deste FAQ e dos demais materiais deste site podem ajudá-lo a decidir se é ou não é assexual. Se você considera que o rótulo de assexual é o que melhor descreve você, você pode escolher se identificar como assexual. (AVEN, c20o12012, General FAQ, 'Am I Asexual?', tradução nossa).

Na construção de uma autoidentificação assexual, Chu (2014) descreve que nas páginas do site da AVEN e na seção de perguntas (FAQ) encontram-se múltiplas formas de experiência assexual, como excitação, masturbação, possibilidade ou não de comportamento sexual e desejo ou não de ter um parceiro romântico. Ela relata resistência a uma identificação medicalizada, com critérios a serem seguidos, pensando a identidade assexual como um construto, pois sua autoidentificação é vital para a percepção da sua assexualidade.

A comunidade assexual amplia o leque da assexualidade ao criar possibilidades como a "área cinza" (gray area). As pessoas pertencentes a essa área estariam entre os assexuais e os não assexuais. Essas pessoas experimentariam atração sexual em situações específicas, como é o caso dos Gray-A e dos Demissexuais. Os Gray- $A$ seriam pessoas que teriam níveis de atração sexual flutuante, passando por determinados períodos em que ficam sem ter relações sexuais. Os Demissexuais se identificam como pessoas que têm envolvimento sexual, mas exclusivamente quando há envolvimento afetivo. Dessa forma, amplia-se o escopo de pessoas que podem estar dentro de um viés assexual (Scott \& Dawson, 2015).

Nessa perspectiva, criam-se palavras-conceito para os estudos da (as) sexualidade. Os assexuais se identificam como heterorromânticos, homorromânticos, bi-romanticos e arromânticos, entre outras classificações. Esse hibridismo assexual desestabiliza os teóricos LGBTIQ, pois amplia a possibilidade de pensar a sexualidade (Chu, 2014). Tal possibilidade é de que a assexualidade possa trazer uma perspectiva

$2 \mathrm{O}$ texto em língua estrangeira é: "The definition of asexuality is 'someone who does not experience sexual attraction'. However, only you can decide which label best suits you. Reading this FAQ and the rest of the material on this site may help you decide whether or not you are asexual. If you find that the asexual label best describes you, you may choose to identify as asexual." 
subversiva aos modelos convencionais e míticos sobre conjugalidadeeàs representações standards, a partir de um viés heteronormativo. O interessante é observar, nesse contexto, como as relações assexuais podem evidenciar uma linha tênue entre as relações de amizade e as relações românticas e redesenhar uma nova linguagem sobre afetividade e parcerias. Pode-se, então, perceber várias formas de relacionamento não como algo estável, mas como uma prática contingente, que emerge a cada dia, abrindo-se a diversas possibilidades (Scott \& Dawson, 2015).

Outra perspectiva é pensar a assexualidade e suas formas como parcerias para além do campo do real, expandindo perspectivas para ações afirmativas dentro do mundo, do ciberespaço e do contemporâneo.

Espaços cibernéticos, como o da Asexual Visibility \& Education Network (AVEN), mantidos por usuários globais em sites multilíngues, proporcionam um fórum para afirmar, contestar, e definir o que significa chamar a si mesmo de assexual, pertencer a um grupo de identidade, e coletivamente constituir uma orientação sexual. (Kim, 2014: 249, tradução nossa). ${ }^{3}$

Assim, como a autora afirma, o mundo do ciberespaço tenta trazer uma visibilidade à assexualidade como orientação sexual. Nesse movimento, existem entraves e bloqueios, mas podemos afirmar que a AVEN tem, como uma de suas funções, dar visibilidade a esse coletivo marginalizado. Nessa tentativa de utilizar a internet como espaço de veiculação identitária, vemos certo abandono desse grupo, tanto pelo meio acadêmico quanto por grupos sociais marginalizados, como gays e lésbicas (Grupta, 2014).

Podemos ampliar a leitura política ao entender a assexualidade em um diálogo com Michel Foucault, cujo pensamento rompe com as posturas hierarquizantes do saber e de sua produção, trabalhando com o desvio, com o não dado. Esse movimento precisa ser feito para desmontar a ideia de totalidade, uma vez que as críticas devem ser particulares e locais. Além disso, na produção de conhecimento, é preciso favorecer a emergência dos saberes dominados e relacionar os saberes eruditos aos saberes comuns das pessoas (Foucault, 2004). Nesse sentido, podemos abordar a emergência da assexualidade, dentro de um contexto histórico, devido ao jogo de forças das quais fazem parte a AVEN e as comunidades do Facebook, que são voltadas para esse público e/ou formadas pelos próprios assexuais. Como fenômeno próprio da polimorfia da sexualidade, o encontro com um não desejo sexual pode abrir outras possibilidades de produção de subjetividade que não são necessariamente ruins, mas nos fazem pensar o estatuto desse corpo assexual e o que ele transgride como potência de vida.

3 No original: "Cyberspaces, such as the Asexual Visibility \& Education Network (AVEN), maintained by global users on multi-lingual sites, provide a forum for affirming, contesting, and defining what it means to call oneself asexual, to belong to an identity group, and collectively constitute a sexual orientation." 
Outro olhar é fornecido por Fahas (2010), que abre uma discussão das feministas radicais, como Valeria Solanas, entre outra, a respeito de uma postura ético-política sobre a assexualidade. Em primeiro lugar, ela traz a divisão entre o celibato, onde há uma escolha pelo não sexo e a assexualidade como postura de vida. Essa autora vê a assexualidade como postura sexual e política, importante no contemporâneo. Ela faz uma divisão entre o sexo vaginal ligado ao patriarcado e processo de procriação e ao casamento e o sexo ligado ao clitóris como um caminho à liberdade e de não submissão ao outro para o seu prazer. A assexualidade seria uma potente força contra o sexo como instituição estatal e o controle do patriarcado. Algo importante que a assexualidade tem um poder de subversão entre as outras identidades queer, pois ela quebra com instituições importante como a família e uma visão heterocêntrica do sexo como vetor da vida.

[...] a assexualidade é uma ferramenta de empoderamento e tem elementos de sátira, e talvez até mesmo loucura, Solana argumentava que as mulheres só podiam alcançar a liberdade pessoal ou uma gratificação própria por meio da recusa do sexo (Fahs, 2010:452, tradução nossa).

Nessa produção histórica, podemos dialogar com o pensamento de Giddens (1993) com o nascimento do amor romântico e a divisão entre os assexuais românticos e arromânticos. Conforme esse autor, os casamentos tinham, na Europa pré-moderna, cunho econômico e era entre a população pobre que se organizava a distribuição do trabalho agrário. Devido à carga horária extenuante, era improvável que os casamentos conduzissem à paixão sexual. Não podemos afirmar que não existisse um protorromance, mas podemos afirmar que as práticas sexuais e carícias eram raras: "Tem sido relatado que entre os camponeses da França e da Alemanha do século XVII, o beijo, a carícia, o sexo era raros entre os homens casados." (Giddens, 1993: 49).

Sobre o surgimento do amor romântico podemos afirmar que este tem influência no começo da literatura romântica, assim como em aspectos ligados à criação do lar. Nesse momento, há uma "invenção da maternidade”, com o consequente declínio do poder patriarcal. Nessa propagação da maternidade, alimentam-se alguns valores do amor romântico. É necessária essa problematização, pois, se o amor romântico não é algo naturalizado e de uma origem biológica, podemos pensar se houve algum momento no qual o romantismo se ligou à assexualidade, sendo uma marca forte. Assim, uma vez que o amor romântico se relaciona com um lugar dentro do mundo, no qual as pessoas se identificam como românticas, podemos dizer que houve uma invenção, ou melhor, uma produção de novos afetos.

Nesse percurso do nascimento do amor romântico, "a fusão do amor dos ideais do amor romântico e da maternidade permitiu às mulheres novos domínios de intimidade" (Giddens, 1993: 57). Nos seus primórdios, o amor romântico suscita uma questão de intimidade, mas ele é incompatível com a luxúria. Com isso, corrobora-se 
com as histórias românticas em que as mulheres conhecem o seu príncipe e, a partir desse encontro, traça-se uma biografia mútua (Giddens, 1993).

A assexualidade, romântica ou não, tenta não se ligar à luxúria. No caso dos demissexuais, a sexualidade está sempre atrelada ao vínculo afetivo, expulsando o lascivo, o carnal, romantizando o sexo, sendo uma condição sine qua non para o envolvimento afetivo. Nos assexuais héteros, homorromânticos ou bi-românticos essa linha do amor romântico é algo preponderante assim como nos primórdios há um descolamento da relação romântica, de um envolvimento sexual, para um envolvimento mais afetivo.

Certo é que a assexualidade se configura como um campo de tensões e estranhamentosno qual os limites entre o assexual e o sexual, o normal e o patológico, arepressão e as práticas amorosas são tênues. Diante de tal fato, é possível considerar que estudar a assexualidade ainda é um desafio. Por isso, apresentamos a seguir algumas respostas provisórias para estas questões.

\section{Sobre como conhecer a Assexualidade na contemporaneidade}

Para pesquisar a emergência da assexualidade na contemporaneidade e suas relações com um site e comunidades em redes sociais que versam sobre essa temática optamos por utilizar uma pesquisa de cunho qualitativo. No contexto das pesquisas qualitativas, trabalhamos com a netnografia. Segundo Hine (2000), um dos fatores que abriram o campo da etnografia para outras possibilidades foi a crise do processo etnográfico impactado pelas crises da representação, da legitimação e da práxis. Em decorrência disso houve uma tentativa de aproximação da internet com o espaço físico tendo em vista que, em ambos, ocorrem interações sociais, podendo também a internet se constituir em espaço de observação por parte do pesquisador. Segundo a autora, a etnografia tem deixado para traz os artefatos pré-existentes e se reconfigurado mediante o viés do pesquisador, o que favorece sua realização com uma reformulação do projeto etnográfico sob a luz dos objetos atuais.

Nesse sentido, a netnografia é uma pesquisa observacional mediada pelo campo online que utiliza as comunicações e observações mediadas pelo computador. O instrumento para utilização da netnografia é a observação do meio online como um fenômeno cultural e comunal. Dessa forma, as comunicações mediadas por computador devem ter como estratégia desde a coleta de dados até a triangulação entre diversas fontes off-line e online, como efetuamos no presente estudo. A coleta de dados é adaptada da etnografia face a face, mas com diferente viés metodológico, devido ao meio utilizado (Kozinets, 2014). É rica a observação que se realiza na interação entre os atores mesmo que, para alguns olhares, essas relações possam ser estáticas dentro das comunidades virtuais. Os usuários tentam colocar suas emoções codificadas em palavras, por meio do uso da linguagem. Muitos, apesar de nem se conhecerem, criam uma intimidade virtual e, apesar da distância entre eles, podem 
interagir, sofrer, chorar junto, nas entrelinhas do escrito. Assim, há subjetividade que vaza pelas telas através das redes sociais, principalmente quando as comunidades se entremeiam com a vida, como é o caso da assexualidade.

Outro ponto importante é a diferenciação que Kozinets (2014) faz entre a pesquisa das comunidades online e a pesquisa online das comunidades. O primeiro é voltado para o estudo do mecanismo das comunidades eletrônicas, pois o foco está na comunidade online como, por exemplo, um campo de discussão de novelas online. Já as pesquisas online das comunidades "[...] examinam algum fenômeno social geral cuja existência social vai muito além da internet e das interações online, ainda que essas interações possam desempenhar um papel importante com a afiliação do grupo" (Kozinets, 2014: 65). Essa explicação demonstra que as pesquisas online das comunidades tentam trazer as discussões que são contemporâneas, mas que são mediadas por computador, como nos fala Novelli (2010: 109):

[...] os mundos, online e off-line, não são necessariamente realidades separadas - mundo real versus mundo virtual - mas podem ser considerados um continuum da mesma realidade. De tal forma, o pesquisador deve desenvolver técnicas que o permita analisar esse continuum. Nesse sentido, é interessante notar que, dentre as comunidades ou os grupos que um pesquisador viria a estudar, pode-se destacar os puramente virtuais, ou seja, que são socialmente criadas no ambiente virtual; as que são construídas tanto online quanto off-line; e as que são construídas puramente off-line, ou seja, no ambiente físico.

Outra característica relevante é o cuidado que o netnógrafo deve ter ao escrever sobre as pessoas que pesquisa, evitando jargões objetificantes e a criação de estereótipos. Isso porque a netnografia visa transmitir uma visão sensibilizada e personalizada do fenômeno cultural que pesquisa. Assim, de acordo com Kozinets (2014: 156):

[...] uma comunidade online desempenha um papel profundo e importante na vida das pessoas - e também quando torna um aspecto desconhecido daquela cultura em algo mais íntimo. Uma história netnográfica é evocativa, ressonante quando toca as nossas próprias vidas, fazendo que o confortável e próximo de nós parece distante e bizarro.

Nesse contexto, em nossa pesquisa de campo, abordamos dois focos: comunidades virtuais e entrevistas com sujeitos quese identificam com a assexualidade. No primeiro, utilizamos como metodologia a etnografia virtual de Hine (2004) e a netnografia de Kozinets (2014). No segundo, foram feitas entrevistas semiestruturadas com roteiro previamente elaborado. Os entrevistados selecionados eram participantes das comunidades virtuais do Facebook e autodeclarados assexuais. Foi feita uma 
publicação online (post) convidando pessoas para a entrevista e explicando a finalidade da pesquisa. No início da entrevista, foi assegurado aos participantes que um feedback de sua participação ocorreria e também seria enviada uma cópia da dissertação para cada um dos participantes. ${ }^{4}$

Ao tentar adentrar no mundo da assexualidade, o mais difícil foi o acesso a essas pessoas que se autoidentificam como pertencentes ao espectro assexual. Verificamos que há várias comunidades no Facebook sobre assexualidade no Brasil. Inscrevi-me em três e, ao ser aceito, me apresentei como pesquisador, dizendo que iria realizar uma dissertação acerca do tema. A recepção nas comunidades me surpreendeu: todos se colocaram à disposição para ajudar na pesquisa e, em suas falas, um dos tópicos era a invisibilidade da assexualidade como orientação sexual. Um fato importante nessas comunidades é a classificação dentro do mundo aces. As leituras anteriores à imersão no campo foram essenciais, pois o mundo ace é bastante codificado, com códigos de conduta dentro da própria comunidade. Justamente por isso notamos que a moderação é bastante ativa e qualquer membro que coloque algum conteúdo considerado impróprio é banido do grupo.

A imersão no campo foi de interação, em alguns momentos, e de observação participante em outros. Conforme Dias (2015) existem dois tipos de pesquisas netnográficas, o lurking, ficar à espreita, observando, e o insider, cuja interação é muito maior. Na postura de pesquisador, houve trânsito entre os dois polos, às vezes realizando perguntas, às vezes interagindo, mas sempre com muito cuidado, para que a voz naquele espaço não fosse uma voz de saber ou de especialista, como definido por Foucault (2011), saber que, muitas vezes, se coloca como totalizante e (como efeito de) verdade, impedindo a emergência dos saberes dominados, que não pertencem às práticas discursivas da ciência.

Retornando ao campo, através de anotações e da observação participante, mantivemos uma frequência quase diária durante os meses de novembro e dezembro de 2014. Ao todo, foram realizadas quatro entrevistas e as conversas copiadas eram datadas, acrescentando impressões sobre o fato ocorrido na comunidade. No presente trabalho apresentaremos duas. Outro ponto a ser destacado foram os entraves na busca para a pesquisa off-line. Apesar de o discurso da assexualidade ser a favor da visibilidade, experimentamos dificuldade em encontrar pessoas disponíveis para o contato face a face. Durante a abordagem para a entrevista, quando me identificava como psicólogo, muitos mostravam relutância devido a ideias pré-concebidas de que seriam analisados ou de que teriam sua sexualidade diagnosticada como doença. Tal resposta é um dos elementos que mostra os entraves da pesquisa, embora possa fazer emergir debates. Acerca dessas situações, podemos afirmar que

4 Essa pesquisa foi ainda aprovada pelo Comitê de Ética Em Pesquisa (CEP) sob registro número CAAE : № Registro CEP:40808314.5.0000.5137.

5 Segundo Capell (2016: s. p) "Em inglês, a pronúncia da primeira parte do nome 'asexual' é 'ace', que em inglês, é a forma de se chamar a carta "ás" do baralho. Com isso, ás se tornou o símbolo para os assexuais. O de copas para os românticos e o de espadas (que parece um coração de cabeça para baixo) para os arromânticos. Os assexuais se chamam de ace". 
[...] são os dispositivos analisadores criados pelo analista e o coletivo para deflagrar o processo de análise: o resultado de uma pesquisa quantitativa e qualitativa, a exibição de um filme, um psicodrama, etc. Espontâneos, por sua vez, são os fenômenos que fazem parte do cotidiano das organizações institucionais: os fundadores, a missão, o poder, o dinheiro, a sexualidade, a burocracia (leis, normas, regulamentos e constituições), a corporeidade, as práticas do estabelecimento. (Pereira, 2007: 14).

Em contrapartida, alguns entrevistados, apesar da reação inicial, viram algumas perguntas minhas nas comunidades virtuais e começaram a querer participar da pesquisa. Nesse contexto, sustentando todo esse plano de forças, este estudo privilegia a pesquisa online em comunidades, embora a assexualidade seja um fenômeno que ultrapassa a internet e as interações online. Os resultados desse processo de investigação serão apresentados parcialmente a seguir.

\section{(Des) conhecendo a sexualidade}

Já no final da coleta de dados que, de fato, funcionou como uma produção de dados, na qual se associavam a subjetividade do pesquisador, as narrativas dos informantes e os estudos realizados, agradeci aos usuários, comunicando que estava acabando o meu tempo de observação-interação naquela comunidade. Algo instigante foram os pedidos de devolução da pesquisa, de quais seriam suas conclusões, a vontade de saber onde seria publicada. Um usuário publicou um post: “Tomara que a Psicologia não nos veja mais como pessoas com problemas”. É importante perceber a voz de verdade que o especialista, o Psicólogo e a Psicologia, que sustenta sua prática discursiva, trazem, nesse viés, para a sexualidade, como essa prática pode ser libertadora, mas também pode atuar como uma máquina de fazer corpos pedagogizados, dependendo das circunstâncias e das relações que são estabelecidas. Essa fala deve ser problematizada no papel da Psicologia em vários campos. É dessa forma que aqui trazemos a sexualidade, cujas manifestações não devem ser encaradas como uma verdade absoluta ou enquadradas em possíveis processos de cura, que possibilitem a produção de uma suposta felicidade via interdição e práticas clínicas de dessubjetivação. Com isso, percebemos a Psicologia como algo que transversaliza a vida, como uma prática intercessora que sustenta novos mundos possíveis, mas que, muitas vezes, captura-a em normas, produzindo modos de subjetivação, gerenciando o cotidiano das pessoas, sujeitando-as a verdades normativas que prefixam suas existências e as suas relações. Acerca da norma, podemos afirmar que: 
[...] o elemento que vai circular entre o disciplinar e o regulamentador, que vai se aplicar, da mesma forma, ao corpo e à população, que permite a um só tempo controlar a ordem disciplinar do corpo e os acontecimentos aleatórios de uma multiplicidade biológica, esse elemento que circula entre um e outro é a «norma». A norma é o que pode tanto se aplicar a um corpo que se quer disciplinar quanto a uma população que se quer regulamentar. (Foucault, 1999: 302).

Neste contexto devemos ressaltar a importância o trabalho do psicólogo social. Como exemplo da importância de tais investigações, temos o estudo de A. F. Bogaert (2004) que buscou descaracterizar o "transtorno hipoativo sexual" e o "transtorno de aversão sexual eassexualidade". O autor relata que essas patologias estariam associadas ao aumento da ansiedade experienciado ao se relacionar sexualmente com outros parceiros. No que concerneà assexualidade, tratar-se-ia da falta de desejo sexual. Com isso, afirma que a falta de atração sexual não designa a falta de comportamento sexual.

No seu estudo, Bogaert (2004) relata que cerca de 1\% da população da Inglaterra seria assexual. Ele afirma que pessoas com menor nível de escolaridade e classe social mais baixa teriam maior tendência a serem assexuais. Ademais, não se pode deixar de assinalar que ele trabalha com uma amostra específica, em uma contextualização histórica e geográfica que não pode ser universalizada para outras realidades espaçotemporais. O autor pontua ainda: "Talvez este grupo [assexuais] é relativamente invisível, porque suas inclinações não conduzem a atividades sociossexuais que lhes trariam atenção" (Bogaert, 2004: 280, tradução livre). ${ }^{6}$ Neste caso é possível destacar que a importância da pesquisa foi desencadear o processo de despatologização da assexualidade e sua legitimação como sexualidade abrindo um leque para pesquisadores posteriores, como Nicole Prause \& Cintia Graham (2007).

Hoje, de acordo com o DSM V, as patologias associadas ao desejo são classificadas como "transtorno de excitação ou desejo feminino" e "transtorno do desejo sexual masculino hipoativo". Nesse manual, os processos são patológicos porque estão relacionados a uma condição médica, como depressão ou uso de medicamentos, como antidepressivos. No entanto, a característica que afasta essa condição da assexualidade propriamente dita é um mal-estar geral, por parte dos indivíduos, em relação a essa condição, interpretada como falta ou diminuição do desejo sexual. Segundo Cerankowski \& Milks (2010), esses transtornos relatados por Prause tentam ser mais "amigáveis aos assexuais", mas ainda não proporcionaram a retirada deles como uma categoria do DSM.

Na leitura do DSM V, podemos problematizar alguns dos algoritmos que patologizam a falta de desejo. No Transtorno do Desejo Sexual Masculino Hipoativo (TDSMH), no critério A pode ser lido que

6 O texto em língua inglesa é: "Perhaps this group [asexual] is relatively invisible because their inclinations do not lead to sociossexual activities that would bring them attention." 
Pensamentos ou fantasias sexuais/eróticas e desejo para atividade sexual deficientes (ou ausentes) de forma persistente ou recorrente.O julgamento da deficiência é feito pelo clínico, levando em conta fatores que afetam o funcionamento sexual, tais como idade e contextos gerais e socioculturais da vida do indivíduo. (APA, 2014: 441).

Podemos, seguindo essa pista, questionar uma homogeneização da subjetividade promove na prática o negligenciamento da singularidade de corpos. Essa estratégia de padronização demostra que em lugares distantes e específicos possa ser realizada a mesma leitura de uma doença ou de um processo patológico. Almeja-se ainda que o tratamento seja o mesmo em lugares totalmente distintos, que o olhar seja o mesmo (Rauter \& Peixoto, 2009). Nessa pasteurização dos processos de subjetivação, colocamos essas vidas singulares cada vez mais em linhas duras e binárias como doente ou não doente, homem ou mulher através de uma operação na qual a historicidade desses corpos é totalmente renegada ,na qual predomina uma voz de poder a partir da qual o especialista legisla e determina o caminho que os corpos devem seguir.

Com certeza, não podemos designar a sexualidade como linear e universal. Considerando a assexualidade podemos dizer que ela é plural e que sua construção tem também caráter discursivo, pois, nos fóruns do Facebook, as discussões são realizadas, por exemplo, no Brasil, a partir da língua oficial. Essas trocas de experiências regionalizam e criam especificidades. Apesar de a AVEN ter uma forte influência no público ace, essas pessoas são transversalizadas pela vida e por causa de sua heterogeneidade bem como pelos encontros com outros aces, seja off-line, seja online. Nesses encontros, em um rebater entre identidades provisórias, criamse outros rostos, outras corporificações, que vão se fazendo e se desfazendo, como exemplifica a fala a seguir:

Eu acho que não se deixa de ser gay. A pessoa sempre nasceu gay ou hétero. Agora, se deixa de ser Assexual? Será que já nascemos assim ou algum trauma mudou o percurso? Será que o medo de sexo faz as pessoas pensarem que são assexual mesmo não sendo? (V. N., Facebook).

Nesse relato, V.N. discute uma possível essencialização ou não da assexualidade e nessa dúvida traz várias respostas que são díspares, mas falam da história daquele corpo, das reverberações que ele pode suscitar a partir de vivências e silenciamentos. Sua singularização vaza pelos poros e traz uma abertura para várias verdades ou perspectivas desse tema. Na luta pela variação da sexualidade, Foucault (2015), ao discutir a questão da homossexualidade e as verdades sobre ela, faz a seguinte colocação: 
[...] quando mostro o caráter histórico dessa noção, dessa homossexualidade, não é para dizer que vocês se enganaram ao lutar contra ela. Digo, ao contrário, que era mesmo preciso lutar, porque essa noção era a captura histórico-política que se tentou estabelecer quanto a uma forma de experiência, uma forma de relação, uma forma de prazer que se queria excluir. Agora, mais do que a homossexualidade, penso que atualmente a própria noção de sexualidade deve ser verdadeiramente reavaliada, ou melhor, deve-se fazer dela uma nova avaliação. De certa forma, foi absolutamente indispensável, nas lutas precedentes, tomá-la a sério. E dizer: temos diante de nós, ou acima de nós, médicos, pedagogos, legisladores, adultos, pais etc., que falam da sexualidade. Que seja, se vocês querem falar disso, falemos. $\mathrm{E}$ vamos fazer valer os direitos à sexualidade. Está muito bem. Isso não quer dizer que os direitos da sexualidade sejam todos reconhecidos. Digamos que, em todo caso, o combate simultaneamente se ampliou e se solidificou. (Foucault, 2015: 3-4).

Nessa direção podemos entrelaçar ao discurso da assexualidade o discurso da homossexualidade, com a afirmação da assexualidade como um modo de vida. Ao falarmos hoje em sexualidade temos reconhecer a necessidade de abertura para a existência de um polimorfismo do qual não dão conta as letras na sigla LGBTIQ. Assim, abrimos um leque para pensarmos em uma assexualidade rizomática, com ajuda de Deleuze \& Guattari (1995), em Mil Platos I. A ideia de rizoma foi retirada pelos autores da Botânica e corresponde a uma rede de relações. Essa rede se autoproduz por conexões e agenciamentos com diversos elementos da realidade, aos quais se conecta e reconecta-se incessantemente, não havendo, portanto, remissão a uma unidade. Essa dinâmica de autoengendramento é incessante e nos remete a forças/fluxos que não têm forma e nem limites pré-determinados. Tal concepção atribui à subjetividade um caráter mutável, permite deslocamentos que se libertam das estruturas cristalizadas baseadas em modelos reprodutivos e que impedem a invenção. Nessa perspectiva a assexualidade é coextensiva e aberta em múltiplas possiblidades.

Um rizoma não começa nem conclui, ele se encontra sempre no meio, entre as coisas, inter-ser, intermezzo. A árvore impõe o verbo "ser", mas o rizoma tem como tecido a conjunção "e...e...e..." Há nessa conjunção força suficiente para sacudir e desenraizar o verbo ser. [...] Entre as coisas não designa uma correlação localizável que vai de uma para outra e reciprocamente, mas uma direção perpendicular, um movimento transversal que as carrega uma e outra, riacho sem início nem fim, que rói as margens e adquire velocidade no meio (Deleuze \& Guattari, 1995: 37) 
Consoante a este pensamento, realizamos algumas entrevistas presenciais com pessoas que faziam parte do grupo dos assexuais do Facebook. A um dos entrevistados chamaremos de Ace Return. Ace Return, 20 anos, é paulista, morador, no momento da entrevista, da cidade do Rio de Janeiro, onde realizava o seu mestrado em Engenharia. A entrevista foi marcada em um local público, mas ele nos pediu por meio do aplicativo de celular WhatsApp que fôssemos a algum lugar que "não pudessem ouvir a nossa conversa". Ao chegar ao local encontramos um rapaz de altura mediana, de óculos, simpático e solícito. Antes de iniciar a entrevista, ele relata que não tinha problemas em falar de sua assexualidade, mesmo que a maioria das pessoas desconhecessem sua orientação sexual ou achavam graça dela. Ao perguntarmos a ele como foi essa identificação ele nos respondeu que se considera um "assexual diferente". Na sua primeira fala ele nos diz:

Na verdade, veio de uma decepção amorosa que eu tive. Eu namorei por nove anos, e com esse término de relacionamento [corte no áudio] um pouco. Entrei em depressão e depois disso eu não consegui mais ter desejo sexual, nem atração sexual por ninguém, por mais que já tenha tido relações depois disso, mas eu vi que não fazia mais propósito, entendeu? Não tinha mais sentido pra mim, não sentia mais atraído [...] E em reflexão aos meus 9 anos, eu também não tenho certeza até que ponto eu tive prazer sexual nesse relacionamento e até que ponto eu simplesmente cedia em nome do amor ali envolvido, entendeu? (Ace Return) ${ }^{7}$

Para Ace Return, a assexualidade veio em meio a sentimentos profusos entre o amor romântico e um não desejo. O processo depressivo pode ter sido deflagrado por um término de relacionamento, mas, de algum modo, influencia encontros potenciais na vida. Ele começa a escutar seu corpo, que parece não ter sido ouvido durante os nove anos de relacionamento. Seu questionamento sobre ceder por amor é bastante emblemático, pois suas sensações eram solapadas pelo amor que sentia. Isso nos faz pensar até que ponto sentimentos como amor e desejo podem ser separados e se há momentos em que eles se misturam, tornando essa mistura híbrida, sem que seja possível separá-los. Na continuação da entrevista, pergunto se o desejo sexual é algo que ele não sente:

Eu acredito que sim. Ou, se eu não venha a ter, eu posso, é... Adequar igual a esses nove anos, foi, foi meio que uma adequação eu acredito, entendeu? Então eu acho que pode ser mais uma coisa adequada ali, que não tenha tanta complicação assim... Mas hoje em si eu não me vejo tendo uma relação sexual com ninguém $\operatorname{assim...~(AceReturn).~}{ }^{8}$

7 Dados da entrevista. Pesquisa de campo

8 Dados da entrevista. Pesquisa de campo. 
Ele considera o seu relacionamento de nove anos como uma adequação ao mundo sexocêntrico, havendo uma obrigação marital para com seu parceiro, em que sua voz era silenciada. Contudo, Ace Return não vê a assexualidade como algo standard, ou algo inato. Podemos dizer que ele tem momentos nas tonalidades cinza da assexualidade, mas, no seu discurso, de modo geral, traz uma linha de ruptura com a possibilidade de se permitir ao desejo sexual. Indagado acerca do viés singular da assexualidade ele fica em silêncio, pode ser notado um rubor em sua face e ele me responde:

Eu no singular? Porque eu vejo muito rótulo a pessoa ser assexual, não sentir atração sexual por pessoas, por nada né, [risadas], mas enfim... [risadas]... Depois eles se dividem em românticos, arromântico, homorromânticos, heterorromânticos, bi-românticos. Eu acho que essa divisão, pra mim, não existe. Porque a partir do momento que você não tem atração sexual o sexo não importa. Não faz sentido se for homem ou mulher, não tem diferença, até porque o que um homem tem de diferença da mulher nãoé isso quevocêtá procurando, então, não... Eu acho que isso pra mim não existe, entendeu? Essa divisão. Eu me considero uma pessoa romântica, mas... entre taxar entre heterorromântico, homorromântico ou bi-romântico, eu acho que seria mais biromântico, [rápida pausa], mas não necessariamente... (ACE RETURN)

Ace Return põe em dúvida a classificação da assexualidade da AVEN. Para ele, não há importância em qual orientação romântica ele se encontra, o que traz uma discussão interessante sobre as subclassificações que o sistema heteronormativo nos coloca. Ao se declarar como romântico, ele se abre para as possibilidades de encontros na vida e pela vida. Esse sistema classificatório pode ser totalmente perverso, pois, ao se afirmar assexual, o que seria uma quebra de paradigma, insere-se em outra classificação, que seria a da orientação romântica. Não há uma demonização dessa classificação, desde que não seja algo compulsório, dado ou inato. Na continuação nosso entrevistado afirma que o sexo não faz parte da sua vida.

Dois aspectos nos deixaram intrigados: o primeiro em relação ao deslocamento que Ace Return afirma, na sua relação do não desejo sexual. Como nós vivemos em uma sociedade sexocêntrica ele se coloca à margem, pois o sexo margeia todas as orientações sexuais, como hétero, homo, bi e outras. Contudo, quando pensamos na assexualidade como possível orientação sexual, o A (assexualidade) bagunça e tira o fôlego das letras LGBT.

Agora falaremos do outro entrevistado em que a entrevista foi realizada por Skype $^{9}$. France Ace tem 20 anos, mora em uma cidade periférica de São Paulo e é estudante de Letras: Português - Francês de uma universidade federal do estado de São Paulo. Ele relata que vem de família humilde e mora com seu pai e com sua avó.

9 Dispositivo eletrônico para conferências via web. 
Na entrevista, ele teve de ir para a cozinha, pois dividia seu quarto com ela. Diz ainda que tem um dia muito atarefado, pois a distância entre sua casa e a universidade é considerável.

Antes de iniciar a entrevista propriamente dita, France Ace nos fala: "Olha, (pausa), pode ser um projeto em que as outras pessoas podem se enquadrar, escolho a assexualidade! A assexualidade está ao lado da bandeira LGBTI e como as pessoas entendem (risos). Fico pensando que as pessoas podem ter duas sexualidades" (France Ace). ${ }^{10}$ Essa fala é instigadora, pois France Ace é bem falante, tem um vocabulário amplo. Entretanto, ficamos inquietados com essa questão de duas orientações e perguntamos a ele: você acha que a assexualidade é mais que uma orientação? "Se colocar do lado dos assexuais e de outras nuances, pode ser demi, assexual homorromântico, heterorromântico e o que as pessoas que veem em uma leitura sobre a assexualidade." (France Ace)."

Ficar fora da previsibilidade, principalmente dentro da sexualidade, traz uma incerteza acerca da própria identidade. Acreditamos que, por isso, a identidade da assexualidade trouxe para France Ace um território, um porto seguro em relação ao que ele é, concernente ao sexo. Não estamos hostilizando essa busca pela identidade, pois ela se apresenta coextensiva à busca de visibilidade e, no caso da assexualidade, na sua emergência como orientação sexual.

Perguntamos para France Ace como ele começou a se identificar com a assexualidade: "Na verdade não faz muito tempo. Já estava nesse processo de estar pensando nisso (silêncio) dentro da demissexualidade, que está dentro da assexualidade”. Nessa direção, o contato com a página do Facebook foi libertador como ele mesmo acrescentou, pois ao ver um vídeo sobre demissexualidade, há um transbordamento, algo que se identifica, nessa busca de si. Nesse momento, identificou-se como portador de uma sexualidade.

Indagado acerca de apresentar-se como demissexual e gay, ele responde "Das experiências que eu tentei, das formas muito estranhas, conhecer pessoas pela internet, pois eu acho mais tranquilo. Comecei a andar nesse quesito relacionamento a vida toda, que foi um problema na vida toda" (France Ace). ${ }^{12}$

A internet se abre como uma possibilidade nos relacionamentos na contemporaneidade, pois é nessa relação com o mundo virtual que se criam avatares, perfis e outras possibilidades de construção de si no mundo virtual (Beleli, 2015). Essa identidade mutante visa atender a demanda do usuário e, no caso dos assexuais, um local de acessibilidade, em que algumas questões já estão ditas ou querem ser aprendidas, onde encontros podem ser realizados, amizades podem ser feitas, como nos casos da assexualidade. Podemos pensar nessa dualidade que France Ace vivencia, de ser homossexual e demissexual, o que amplia nosso olhar para essas orientações. Como foi dito, há a necessidade de vínculo afetivo, que margeia as relações demi, seja

10 Dados da entrevista. Pesquisa de campo.

11 Dados da entrevista. Pesquisa de campo.

12 Dados da entrevista. Pesquisa de campo. 
hétero, bissexual ou homo. Insistimos, na entrevista, em saber mais profundamente sobre a comunidade assexual e de que comunidades assexuais ele fazia parte.

Há somente uma comunidade assexual como já havia te dito. Ela é aberta e é mais difundida do que outra, mas tenho outra página que é do assexual orelhudo. Quando entrei lá escrevi um texto que estava, pois estava em um pensamento muito difícil. E aíresponderam, e aí arrumei um colega, que é colega até hoje. Ele me ajudou muito nesse processo de aprendizagem. Outras coisas, que penso de mim, vou construindo. (France Ace). ${ }^{13}$

Nesse aprendizado sobre a assexualidade, nessa construção dentro da demissexualidade, France Ace nos fala de várias dores, sofrimentos e percalços, nos dando pistas de uma sexualidade em trânsito. Louro (2008), ao realizar uma viagem com esses viajantes pós-modernos, nos alerta que "[...] é preciso abandonar qualquer pressuposto de um sujeito unificado, que vá se desenvolvendo de modo linear e progressivo" (Louro, 2008: 12). Tal descentramento do sujeito pode ser percebida na história de France Ace, a partir da manifestação (e discursivização de) uma sexualidade que questiona, transita, se movena margem. Na sua busca incessante por um lugar, por uma identidade que se coaduna com o que sente em seu corpo, ele vai transitando. Esse movimento traz deslocamentos, não a busca de um fim, mas o movimento nos territórios da sexualidade. Nesse pensamento, é preciso "[...] supor que o sujeito que viaja é, ele próprio, dividido, fragmentado e cambiante” (Louro, 2008: 13). Assim, percebemos, nessa busca, sua subjetividade cambiar entre o seu desejo homossexual e a necessidade de vínculo afetivo da demissexualidade. Nessa busca pelas sexualidades em trânsito perguntamos como é a sua interação na comunidade.

Eu não posso postar como fizeram ontem sobre sexo e sobre ficar com pessoas. Eu não posso opinar, pois só tive uma pessoa (EMBARGO NA VOZ). E esta pessoa que tinha todo um problema, tinha sofrido um abuso na infância, e tinha questões dele, em que não soube resolver até hoje. E com isso, sobre relacionamento e o sexo não posso opinar. (PAUSA). Mas deixa o coração saber. (France Ace). ${ }^{14}$

Todavia, France Ace coloca-se em um lugar de não poder falar de sexo, como se, para tal, ele tivesse de ser um especialista sobre sexo e relacionamentos. Nessa perspectiva, percebemos que a demissexualidade se afasta da própria assexualidade, pois a necessidade do ato sexual ultrapassa o biológico, realizado somente mediante vínculo afetivo. Observamos, aqui, a necessidade de quebrar esses estereótipos de gênero. Nessa perspectiva, podemos afirmar:

13 Dados da entrevista. Pesquisa de campo.

14 Dados da entrevista. Pesquisa de campo. 
[...] que estereótipos sexuais ou de gênero referem-se a um conjunto de crenças estruturadas acerca dos comportamentos e características sexuais adquiridos ao longo do processo de socialização realizado por agentes, como a família e a escola, que transmitem valores e convicções por meio dos estereótipos. (Reis\& Maia, 2009: 138)

Percebemos que France Ace, na sua fala, traz, entrelaçado com sua história e seus olhares, a questão da experiência com parcerias do mesmo sexo. Ele não vê em si uma pessoa que possa opinar sobre algo que não vivenciou. No entanto, em seu relato, sua história afetiva não deve ser descartada, pois ela ocorre no que é possível, ou seja, mesmo que o desfecho não tenho sido o de um casal normatizado, foi o que era possível construir. Realizamos o desfecho da entrevista perguntando o que mudou depois que ele descobriu a assexualidade.

(PAUSA) E que não era tão anormal quanto pensava. Que eu tinha um nome e uma classe que me contemplavam. Acho que libertou. (RISOS) Eu tinha uma orientação muito religiosa na infância, por isso eu olhava muito com uma moralidade da Igreja. Isso me fez pensar em muitas coisas, como eu ficava triste na balada, em quanto as pessoas conseguiram ficar com vários. (France Ace). ${ }^{5}$

Essas marcas que perpassam France Ace e outras pessoas com sexualidade desviantes mostram histórias de vida que se abrem para o novo em um processo de desconstrução ao se perceberem diferentes em sua demissexualidade/ homossexualidadequando não se sentem confortáveis, por exemplo, em uma balada. Diante de tais considerações da presente seção, vale acentuar que as vidas singulares devem ser potencializadas e não corrigidassob a égide de uma falsa percepção do que venha a ser uma verdadeira (sic) assexualidade ou demissexualidade.

\section{Considerações Finais}

Nesse texto, propusemos estudar a assexualidade e a sua emergência na atualidade. Apesar de considerarmos a assexualidade como uma orientação sexual abordamos sua não visibilidade, no escopo de outras orientações sexuais, bem como as relações de força presentes a partir de tal abordagem. Assim, buscamos pesquisar essa orientação sexual em suas relações com um site e com comunidades em redes sociais que versam sobre essa temática. Para isso, foi necessário pesquisar o arcabouço teórico sobre o tema da assexualidade que, em língua portuguesa possui ainda poucas produções, embora haja livros e artigos em inglês, também estudados por nós. Além disso, estudamos a assexualidade no mundo virtual, como sites como a AVEN, sendo este o maior site de conteúdo sobre a assexualidade, e o Facebook. Dentro do Facebook, pesquisamos em comunidades voltadas exclusivamente para a comunidade assexual.

15 Dados da entrevista. Pesquisa de campo. 
Tendo em vista os aspectos observados podemos destacar que a Psicologia tem se aberto a essa temática de forma tímida, mas que mostra a importância de se pesquisar esses temas e outros relacionados à temática de gênero e do estudo das sexualidades considerando a complexidade e as intersecções possíveis de tais campos. Porém, não defendemos a ideia de que haja um psicólogo especialista em "sexo", e sim que esse profissional delineie sua discussão como suporte para as políticas públicas voltadas para o grupo LGBTQIA (Lésbicas, Gays, Transgêneros, Queers, Intersex e Assexuais) acrescentando-se umA como forma provocativa e inclusiva para esse grupo que não desconsidera, portanto, a existência dessa orientação sexual. A assexualidade utiliza e traz a sua emergência no conteúdo online, a nosso ver, nos discursos proferidos e discussões sobre essa orientação, criando, assim, um ciberativismo, como vemos no caso das pessoas que querem realizar um Censo Ace via internet. Nessa discussão da possiblidade da assexualidade como orientação para algumas pessoas pode parecer ambivalente e contraditório uma vez que,por exemplo, no caso dos homossexuais masculinos, o desejo é pelo mesmo sexo. Contudo, nos assexuais considerando tanto a pluralidade das práticas como as outras orientações esse desejo verte para um não desejo, num plano de imanência que pode ser uma forma de olhar e se implicar na vida.

Para isso, acreditamos ser necessário despatologizar a assexualidade como fez Bogaert (2004). Essa mesma perspectiva também é desenvolvida por autores como Nicole \& Prause (2007). Ao dar voz aos sujeitos que possuem essa orientação sexual podemos perceber que algumas falas no Facebook mostram o processo de identificação aos seus pares como algo relevante. Vemos que muitas dúvidas estão relacionadas à criação desse corpo assexual, como sentimentos, masturbação, preliminares antes do sexo e outros assuntos. Outro fator importante é a existência de veículos de acessibilidade através dos quaisse criam possibilidades de busca de parcerias, de amizade e derelacionamento. Desse modo, a assexualidade, para muitos, surge como uma tensão entre processos de subjetivação inéditos em sua relação com a internet, sendo esta valorizada para essa descoberta e sua vivência no cotidiano. Nesse sentido, a internet emerge sendo um importante mediador entre a assexualidade e os corpos assexuais.

Os sujeitos entrevistados têm histórias heterogêneas nessa busca do não desejo e as variações que decorrem da vivência da assexualidade. Para muitos, a classificação como assexual trazuma visibilidade de quem ele é e constrói um território no qual consegue habitar e circular.Ao invés de pautas binárias, carne e corpo dicotomizamse, se opõem, se essencializam e, dessa forma, solapam a multiplicidade. Contudo, esse processo dicotômico também cria desvios, que se invertem, se cruzam, se perpassam. É nessa errância que os corpos se recriam, desvinculando-se de um corpo objetificado, no qual essa carne que goza se transporta para um corpo de afetações. As entrevistas permitiram que fosse observada a existência de marcas singulares de viver essa orientação sexual embora os entrevistados ressaltem-na como algo que traz muitos embates dentro do mundo sexocêntrico. Concluímos que há um grande receio da descoberta da assexualidade pelos familiares, pois há uma possibilidade de medicalização e busca de cura.Contudo, percebemos que, para todos os entrevistados, a descoberta e a sustentação da assexualidade, nem que seja para si mesmo, traz um 
território onde é possível viver. Certamente, a assexualidade como orientação sexual é algo novo, a respeito do qual ainda hão de serem feitos diversos estudos e pesquisas a fim de que se possa darvoz a esses sujeitos.

\section{Referências}

AVEN. (2008). The Asexual Visibility E Education Network. so are u a Virgin or NonVirgin Asexual?Disponível em: <http://www.asexuality.org/en/topic/32196-so-are-ua-virgin-or-non-virgin-asexual/> Acesso em: 3 set. 2016.

AMERICAN PSICHIATRY ASSOCIATION. (2014).DSM - 5 - Manual diagnóstico e estatístico de transtornos mentais. 5. ed. rev. Porto Alegre: Artmed.

BELELI, Iara. (2015). O imperativo das imagens: construção de afinidades nas mídias digitais. Cadernos Pagu, n. 44:p. 91-114, jan-jun.

BOGAERT, Anthony. (2006). Asexuality: prevalence and associated factors in a national probability sample. Journal of Sex Research, n. 3, 41: p. 279-287, ago.

BOGAERT, Anthony. (2006). Toward a conceptual understanding of asexuality. Review of General Psychology, n. 3, 10: p. 241-250, ago.

BRIGEIRO, Mauro. (2013). A emergência da assexualidade: notas sobre política sexual, ethos científico e o desinteresse pelo sexo. Sexualidad, Salud y Sociedad, n. 14: p. 253283, ago.

CAPELL, Sha. (2016). Símbolos da assexualidade. Disponível em: <http://www. assexualidade.com.br/2016/og/simbolos-da-assexualidade.html> Acesso em: 27 mai. 2018.

CARRIGAN, Mark. (2013). Asexuality and its implications for sexuality studies. Psychology of Sexualities Review, n. 1, 4: autumn.

CERANKOWSKI, Karli June \& MILKS, Megan. (2010). New orientations: asexuality and its implications for theory and practice. Feminist Studies, n. 3, 36: p. 650-664, Fall.

CHU, Erica. (2014). "Radical identity politics: asexuality and contemporary articulations of identity”. In: CERANKOWSKI, Karli June \& MILKS, Megan (eds.). Asexualities: feminist and queer perspectives. New York: Routledge. p. 79-99.

DELEUZE, Gilles \& GUATTARI, Félix. (1995).Mil platôs: capitalismo e esquizofrenia. Tradução: Aurélio Guerra Neto e Célia Pinto Costa. Vol. 1. São Paulo: Editora 34. 
DIAS, Vanina Costa. (2015). "Morando na rede”: novos modos de constituição de subjetividades de adolescentes nas redes sociais. Tese (Doutorado em Psicologia) Programa de Pós-Graduação em Psicologia, Faculdade de Psicologia da PUC- Minas, Belo Horizonte, mimeo.

DIAMOND, Lisa M. (2008). Sexual fluidity: understanding women's love and desire. Cambridge: Harvard University Press.

FAHS, Breanne.(2010).»Radical refusals: On the anarchist politics of women choosing asexuality”. Sexualities, n. 4, 13: 445-461, ago.

FOUCAULT, Michel. (1999). Em defesa da sociedade. São Paulo: Martins Fontes. . (2011). Microfísica do poder. Rio de Janeiro: Graal. . (2004).Ética, Sexualidade, Política. Rio de Janeiro: Forense Universitária. (2015). O saber gay. Ecopolítica, n. 11: p. 2-27, jan-abr.

GIDDENS, Anthony. (1993). A transformação da intimidade: sexualidade: amor, erotismo nas sociedades modernas. São Paulo: Editora da Universidade Estadual Paulista.

GRUPTA, Kristina. (2014). "Asexuality and disability:mutual negation in Adam v. Rice and new directions for a coalition building”. In: CERANKOWSKI, Karli June \& MILKS, Megan (eds.). Asexualities: feminist and queer perspectives. New York: Routledge. p. 283-301.

HINDERLITER, Andrew Clinton. (2009a). Asexuality: the history of a definition. Asexual Explorations. Disponível em: <http://asexualexplorations.net/home/ documents/asexuality_history_of_a_definition.pdf>. Acesso em: 12 ago. 2014.

HINDERLITER, Andrew Clinton. (2009b). Methodological issues for studying asexuality. Archives of Sexual Behavior, n. 5, 38: p. 619-621, out.

HINE, Christine. (2004).Etnografía Virtual. Barcelona: UOC.

KIM, Eujung. (2014). "Asexualities and disabilities is constructing sexual normalcy". In: CERANKOWSKI, Karli June \& MILKS, Megan (eds.). Asexualities: feminist and queer perspectives. New York: Routledge. p. 249-282.

KOZINETS, Robert. V. (2014). Netnografia: realizando pesquisa etnográfica online. Porto Alegre: Penso. 
LOURO, Guacira Lopes. (2008). Um corpo estranho: ensaios sobre sexualidade e teoria queer. Belo Horizonte: Autêntica.

MASCARENHAS, Fabiana. Assexuais lutam por respeito e visibilidade. Disponível em: <http://atarde.uol.com.br/cienciaevida/noticias/1708575-assexuais-lutam-porrespeito-e-visibilidade> Acesso em: 30 ago. 2015.

NOVELI, Marcio. (2010). Do off-line para o online: a netnografia como um método de pesquisa ou o que pode acontecer quando tentamos levar a etnografia para a internet? Organizações em Contexto, n. 12, 6: p. 107-133, jul-dez.

OLIVEIRA, Elizabeth, Regina Baptista. (2015). "Minha vida de ameba”: os scripts sexonormativos e a construção social das assexualidades na internet e na escola. Tese (Doutorado em Educação) - Programa de Pós-Graduação em Educação, Faculdade de Educação, São Paulo.

PEREIRA, Willian César Castilho. (2007).Movimento institucionalista: principais abordagens. Estudos e pesquisa em psicologia, n. 1, 7: p. 10-19, jan-jun.

PRAUSE, Nicole \& GRAHAM, Cinthia A. (2007). Asexuality: classification and characterization. Archives of Sexual Behavior, n. 3, 36: p. 341-356, jun.

RAUTER, Cristina \& PEIXOTO, Paulo de Tarso de Castro. (2009) Vida, controle e modulação do contemporâneo. Psicologia em Estudo, n. 2, 14: p. 267-275, abr-jun.

REIS, Kellen Cristina Florentino \&MAIA, Ana Cláudia Bortolozzi. (2009). "Estereótipos sexuais e a educação sexista no discursos da mães”. In: ALLE, Tânia Gracy Martins do (ed.). Aprendizagem e desenvolvimento humano: avaliações e intervenções. São Paulo: Cultura Acadêmica. p. 137-154.

ROTHBLUM, Esther D. \& BREHONY, Kathleen A. (1993). Boston Marriages: romantic but asexual relationships among lesbians. Amherst: University of Massachusetts Press.

SCOTT, Susie \& DAWSON, Matt. (2015). Rethinking asexuality: a simbolic interacionist account. Sexualities, n. 1-2, 18: p. 3-19, fev.

Recebido: 11.09.2017

Aceito: 29.06.2018 